\title{
НЕЭФФЕКТИВНОСТЬ МЕЖДУНАРОДНОГО ПРАВА КАК УГРОЗА СТРАТЕГИЧЕСКОЙ СТАБИЛЬНОСТИ
}

\author{
А. А. Рыбакова \\ Московский гуманитарный университет
}

\begin{abstract}
Аннотация: Данная статья анализирует состояние международного права с точки зрения его эффективности, раскрывая как положительные стороны, так и недостатки.

Текст доклада автора на Общероссийской (национальной) научной конференции «Моисеевские чтения. Культура и гуманитарные проблемы современной цивилизации», которая состоялась 4-5 марта 2020 г. в Московском гуманитарном университете.
\end{abstract}

Ключевые слова: право; международное право; международные отношения

\section{INTERNATIONAL LAW INCAPACITY AS A THREAT TO STRATEGIC STABILITY}

\author{
A. A. Rybakova \\ Moscow University for the Humanities
}

\begin{abstract}
This article analyzes the state of international law from the point of view of its effectiveness, revealing both the positive aspects and disadvantages.

The text of the author's speech at the All-Russian (National) Scientific Conference "Moiseev's Readings. The Culture and Humanitarian Issues of Modern Civilisation", which was held at Moscow University for the Humanities on 4-5 March, 2020.
\end{abstract}

Keywords: law; international law; international relations

За последние десять лет сомнения в целесообразности международного права, его эффективности и слабости, а также прогнозы о его скором крахе стали не просто часто встречающейся, но доминирующей темой высказываний историков, политологов, экспертов и специалистов в области международных отношений. И на это есть довольно весомые причины - громоздкая бюрократизированная Организация Объединенных Наций; попытки установления однополярного мира на базе силового диктата Соединенных Штатов; исламский халифат на Ближнем Востоке, терроризирующий весь мир; «великое переселение народов» на евразийском континенте, непрекращающиеся конфликты регионального и внутреннего характера и т. д. (Сазонова, 2016: Электр. ресурс).

Безусловно, в практике международно-правового регулирования вопрос о действительной эффективности международного права ставится на одно из первых мест, а с ростом значимости международного права в регулировании международных отношений растет и актуальность данного вопроса. На данном этапе современное мироустройство изменяется - мы живем в период интеграции, глобализации, мир становится более целостным, а народы взаимозависимы. Это, во-первых. Во-вторых, современный, более глобальный мир, встречается с глобальными вызовами, с которыми ни одно государство не справится в одиночку. 
Сотрудничество неизбежно и необходимо. И очень важно, чтобы сотрудничество было добровольным на основании равенства интересов.

Международное право с общепризнанными нормами и принципами является базой для сотрудничества. Во многих областях международного сотрудничества государства добросовестно соблюдают международные стандарты, содержащиеся в международных договорах и обычном праве.

Однако, в сфере по поддержанию мира и безопасности, защите прав человека и окружающей среды эффективность международного права низкая. А нормы международного права, запрещающие применение силы в международных отношениях, вмешательство во внутренние дела суверенных государств, по борьбе с международным терроризмом совершенно не справляются с заявленной целью.

К 2020 г. сложилось довольно популярное мнение в обществе, что международное право существует только для «создания вида», и особо крупные политически игроки его совершенно ни во что не ставят. Это не совсем так. Важной чертой международного права является его не вертикальность. Международное право есть ничто иное, чем результат договоренностей, компромиссов исходящих из интересов стран. А самое главное, обществу надо понимать кардинальное различие между международным и национальным правом, в котором нет мирового судьи, в отличие от товарища полицейского. Существует только взаимная ответственность, которую легко объяснить на примере посольств: разгром посольства одной страны приведет к разгрому посольства в другом государстве.

При всем несовершенстве принципов и норм международного права, они на сегодняшний день являются единственно признаваемыми всеми государствами сводом правил, дающим возможность в процессе сотрудничества решать важнейшие проблемы международных отношений. Но для того, чтобы международно-правовые нормы могли успешно выполнять возложенные на них задачи, необходимо повышать их эффективность. Вышеуказанный свод правил, современное международное право, на наш взгляд обладает огромным потенциалом. Нет необходимости создавать что-то новое, нужно достичь результативности того, что уже написано. Основными, более общими, критериями для повышения эффективности международного права является прогресс в развитии международных отношений, достижения их нового качества, в котором существует главенство права, а право силы более лишено своего превосходство. А также развитие самого международного права, путем конкретизации общих принципов и создания новых международных норм, соответствующих назревшим потребностям и изменившимся условиям, с формированием новых и усовершенствованием существующих международных и национальных механизмов имплементации (Мингазов, 2000).

Что есть эффективное право? Почему право неэффективно? Как осуществить соблюдение норм международного права? Эффективное право - право, достигшее социальной реализации своих норм и принципов. Социальная результативность норм международного права - это достижение максимально близкого к намеченному в цели нормы социально-полезного регулятивного воздействия на субъектов международных отношений.

В определенной степени неэффективность международного права может начи- 
наться еще с процесса правотворчества. Правотворчество - начальный механизм в создании системы международно-правового регулирования. Именно на этой стадии выявляется сама необходимость в правовом регулировании чего-либо, характер и содержание, качество правовой нормы, ее обоснованность и степень влияния на участников, а соответственно и ее эффективность. Из чего следует важность развития и совершенствования механизмов международного правотворчества. И надо понимать, что процесс нормотворчества в международных отношениях — это процесс принятия политических решений. То есть в основе этого процесса лежат: политическая воля (опять же), учет чужих интересов, желание сотрудничать и достичь результата, а значить быть готовым к компромиссу или уступке. Слабые механизмы реализации, недостаточная конкретизация в формулировке и т. д. - все это проявления недостаточно сильной политической воли.

Еще одним недостатком в этой же сфере является отсутствие механизмов анализа уже существующих норм, с целью их пересмотра, изменения, обновления или вовсе устранения. С появлением новых вызовов, существование быстро реагирующих механизмов, которые позволяли бы подстраиваться под изменения, является необходимым на наш взгляд. Явным примером тому является существование коллизий между основными принципами в уставе ООН. Несмотря на масштабную дискуссию по этому поводу, никаких реальных действий на практике не предпринималось.

Важная роль в качестве механизма обновления норм международного права принадлежит международным органам и организациям, в рамках которых, следовало бы ввести эффективно действующую систему анализа и оценки действия правовых норм, содержащихся в международных актах (Мингазов, 2000). В качестве механизма осуществления данной задачи могут быть применены переговоры как двусторонние, так и многосторонние, а также необходимо использовать весь потенциал $00 \mathrm{H}$.

Как уже было сказано ранее, на этапе правотворчества решается целесообразность и практическая необходимость формирования и создания правовой нормы. Так вот, важным условием эффективности правовой нормы является то, что онадолжнаотвечатьинтересамгосударств.Высокаязаинтересованностьучастников дает высокий уровень реализации. К сожалению, в современных международных отношениях существуют такие реалии, которые до сих пор не нашли отражение на бумаге. Ещё с прошлого века важную и активную роль не только в международных отношениях, но и в правотворческом процессе принимают международные межправительственные организации. А с недавних пор сильными и влиятельным участниками стали международные неправительственные организации (МНПО) и транснациональные корпорации (ТНК). А среди менее сильных государств МНПО и ТНК обладают большой популярностью. В некоторых случаях деятельность международных неправительственных организаций приводит к осложнениям межгосударственных отношений, именно поэтому формирование международноправовой основы для них имеет большое практическое применение (Капустин, 2014). Отставание международного права от реалий создает возможность для толкования права в своих интересах. И если реалии в лице ТНК и МНПО, до сих пор имеет 
к себе посредственное отношение (возвращаясь к вопросу о заинтересованности = эффективности), не значит ли это, что у государств имеется свой интерес или выгода по отношению к ним? Однако факт существования такой концепции, как транснациональное право является прямой угрозой международному праву, на наш взгляд, эта сфера сотрудничества нуждается в глубоком анализе.

Помимо заинтересованности государства, для осуществления соблюдения международного права, необходимо существование действительной базы международно-правовой ответственности. Право обладает потенциалом для стимулирования правомерного поведения. Эта мотивация включает в себя: нормыдефиниции, рекомендательные, конкретизирующие положения, санкционные, положения договоров о сроках, пространственном действии его норм и т. д. И если мы рассматриваем международное право как юридическую базу, основу международных отношений, то вышеуказанные механизмы также нуждаются в повышении своей эффективности, как и система международно-правовой ответственности в целом.

Наличие строго соблюдаемого уголовного кодекса в национальном праве отдельного государства, определенно не означает его сто процентное соблюдение и упразднение преступности. Однако эффективное международное право гарантирует высокую его реализацию. Соответственно и наоборот, низкий уровень эффективности международного права, а именно: непредсказуемость поведения государств, недоверие - представляет собой только угрозу стабильности в мире. Важно понимать, что серьезными нарушениями являются нарушения, которые влекут за собой возможность использования или использование силы государством или группой государств, но это не означает краха системы международно-правового регулирования в общем. Огромная часть норм международного права в сфере экономики, торговли, коммуникаций и т. д. соблюдаются ежедневно.

\section{СПИСОК ЛИТЕРАТУРЫ}

Капустин, А. Я. (2014) Международное право и вызовы XXI века // Журнал российского права. № 7. С. 5-19.

Мингазов, Л. Х. (2000) Эффективность норм международного права: Теоретические проблемы : дисс. ... д-ра юр. н. Казань.

Сазонова К. (2016) Апология международного права. Почему упреки в его адрес несправедливы [Электронный ресурс] // Россия в глобальной политике. Вып. 4. URL: https://globalaffairs.ru/number/Apologiya-mezhdunarodnogo-prava-18230

Дата поступления: 30.03.2020 г.

Рыбакова Александра Андреевна - магистрант специальности «Международные отношения» Московского гуманитарного университета. Адрес: 111395, Россия, г. Москва, ул. Юности, д. 5. Тел.: +7 (901) 590-48-53. Эл. адрес: rybakova00а@ bk.ru

Rybakova Aleksandra Andreyevna, Graduate Student, specialisation "International Relations", Moscow University for the Humanities. Postal address: 5, Yunosti St., Moscow, Russian Federation, 111395. Tel.: +7 (901) 590-48-53. E-mail: rybakova00a@bk.ru 


\section{Для цитирования:}

Рыбакова А. А. Неэффективность международного права как угроза стратегической стабильности // Научные труды Московского гуманитарного университета. 2020. №2. С. 58-62. DOI: $10.17805 /$ trudy.2020.2.10 